\title{
Configurações
}

Revista Ciências Sociais

$27 \mid 2021$

Vária

\section{Ascensão do "agronegócio" e crise da democracia no Brasil}

The rise of "agribusiness" and the democracy crisis in Brazil

Montée de «l'agrobusiness » et crise de la démocratie au Brésil

Luiz Felipe Ferrari Cerqueira de Farias

\section{CpenEdition}

\section{Journals}

\section{Edição electrónica}

URL: https://journals.openedition.org/configuracoes/12130

DOI: 10.4000/configuracoes.12130

ISSN: 2182-7419

\section{Editora}

Centro de Investigação em Ciências Sociais

Edição impressa

Paginação: 95-110

ISSN: 1646-5075

\section{Refêrencia eletrónica}

Luiz Felipe Ferrari Cerqueira de Farias, «Ascensão do "agronegócio" e crise da democracia no Brasil», Configurações [Online], 27 | 2021, posto online no dia 28 junho 2021, consultado o 30 junho 2021. URL: http://journals.openedition.org/configuracoes/12130 ; DOI: https://doi.org/10.4000/configuracoes. 12130 
Farias, Luiz Felipe Ferrari Cerqueira de - Ascensão do "agronegócio" e crise da democracia no Brasil Configurações, vol. 27, 2021, pp. 95-110.

\title{
Ascensão do "agronegócio" e crise da democracia no Brasil
}

\author{
LUIZ FELIPE FERRARI CERQUEIRA DE FARIAS*
}

Universidade de São Paulo (USP)

\begin{abstract}
Resumo
Ao longo deste artigo buscaremos apresentar o "agronegócio" no Brasil como expressão de um curto-circuito no processo de modernização social neste país, onde elevados padrões de produtividade exigidos por cadeias produtivas internacionais de commodities perpetuam e mesclam-se de modo indissociável a traços mais violentos de nosso passado histórico colonial e escravista. Sustentaremos a hipótese de que a consolidação do complexo de relações econômicas e políticas chamado de "agronegócio" esteve na base da atual crise política neste país, codeterminando a queda dos governos de centro-esquerda vinculados ao Partido dos Trabalhadores e o ascenso de forças políticas autoritárias com a eleição de Jair Bolsonaro à presidência da República em 2018.
\end{abstract}

Palavras-chave: agronegócio, reforma agrária, democracia, autoritarismo.

\begin{abstract}
The rise of "agribusiness" and the democracy crisis in Brazil

In this article we will present the Brazilian "agribusiness" as an expression of a short circuit in the process of social modernisation in this country, where the high standards of productivity required by international commodities production chains inseparably perpetuate and blend in with the most violent traits of our colonial past. We will support the hypothesis that the consolidation of the economic and political relations called "agribusiness" was at the base of the current political crisis in Brazil, co-determining the fall of the centre-left governments linked to the Workers' Party and the rise of authoritarian forces with the election of Jair Bolsonaro to the presidency in 2018.
\end{abstract}

Keywords: agribusiness, agrarian reform, democracy, authoritarianism. 


\begin{abstract}
Resumé
Montée de "l'agrobusiness » et crise de la démocratie au Brésil

Dans cet article, nous présenterons « l'agrobusiness » brésilien comme l'expression d'un court-circuit dans le processus de modernisation sociale de ce pays où les normes de productivité exigées par les chaînes internationales de commodities perpétuent et se mélangent inextricablement aux traits les plus violents de notre passé historique colonial et esclavagiste. Nous soutiendrons l'hypothèse que la consolidation des relations économiques et politiques dites d'«agrobusiness » a été à la base de la crise politique actuelle dans ce pays, co-déterminant la chute des gouvernements de centre-gauche liés au Parti des Travailleurs et la montée des forces autoritaires après l'élection de Jair Bolsonaro à la présidence de la République en 2018.
\end{abstract}

Mots-clés: agrobusiness, réforme foncière, démocratie, autoritarisme.

\title{
Introdução
}

A perspectiva político-metodológica que orienta este artigo propõe-se inspirada no marxismo de Henri Lefebvre, especificamente em sua leitura acerca da articulação de contradições sociais de diferentes tempos históricos em uma mesma formação econômico-social. Recuperando as elaborações de Lênin acerca desta noção estabelecida inicialmente por Marx, Lefebvre afirma que o desenvolvimento histórico da acumulação capitalista não avança uniformemente como na abstração (científica, porém incompleta) presente em " $O$ Capital" (Lefebvre, 2013: 359). Se em alguns países e regiões o capitalismo foi em grande medida capaz de fazer tábula rasa daquilo que o precedeu, em países periféricos, especialmente, a expansão das relações capitalistas de produção não destruiu relações sociais antecedentes, antes as conservou e subordinou a sua dinâmica. Segue-se daí, portanto, que formações econômico-sociais com diferentes trajetórias são compostas de distintas sedimentações de dilemas históricos sucessivos, mantidos sem solução no interior da ordem burguesa capitalista. Esta perspectiva metodológica destaca o caráter multiforme de tensões sociais ocultas sob a aparente homogeneidade e linearidade do crescimento econômico e do progresso tecnológico.

Especial mas não somente em países periféricos como o Brasil, o bloco histórico entre burguesia e aristocracia fundiária transformou ao longo do século $\mathrm{XX}$ a apropriação da renda da terra em um dos principais fundamentos para a formação do capital industrial. Isso significa que a generalização do mercado de trabalho livre assalariado foi acompanhada da reprodução de relações de produção e da intensificação de conflitos sociais envolvendo famílias de trabalhadores rurais com acesso parcial e precário à terra. $\mathrm{O}$ chamado "agronegócio" no Brasil corresponde deste modo a um complexo de relações sociais que mesclam de maneira indissociável elevados padrões de produtividade exigidos 
por modernas cadeias produtivas transnacionais aos violentos conflitos envolvendo a posse e a propriedade da terra, principalmente em regiões de fronteira agrícola. Dentro deste contexto, veremos que a resiliência da estrutura fundiária ultraconcentrada e da violência impune contra trabalhadores rurais ao longo das últimas quatro décadas teve como consequência uma identidade nacional continuamente abortada, frustrando parcela importante das perspectivas de transformação social inauguradas com a "Nova República".

\section{Consolidação da economia e da sociedade do "agronegócio" no Brasil}

A década de 2000 foi marcada por uma elevação geral do preço das commodities agrícolas e agro processadas no mercado mundial e pela emergência dos chamados "biocombustíveis" ou "combustíveis verdes" enquanto pauta global do capital. A perspectiva de escassez de combustíveis fósseis, somada à instabilidade de seu mercado, estimulou a busca de fontes de energia a partir de produtos vegetais com fortes impactos sobre a distribuição de lavouras e sobre as correlações de forças no campo brasileiro. Paralelamente, investimentos especulativos em preços agrícolas e os processos de industrialização e urbanização acelerado da China e Índia abriram um cenário favorável no mercado internacional às burguesias agrária e agroindustrial de países como o Brasil. Em uma transformação geopolítica de consequências ainda imprevistas, a parcela dirigida à China (incluindo Hong Kong e Macau) de todas as exportações brasileiras aumentou de 2,8\% em 2000 para 27,9\% em 2018, enquanto a participação dos EUA dentro deste conjunto caiu de $23,9 \%$ para $12 \%$ no mesmo período, conforme mostra o gráfico 1 abaixo. Este incremento das relações comerciais com a China levou a um aumento da exportação brasileira de produtos básicos como minério de ferro e soja em grãos e ao aumento de importações, especialmente de produtos manufaturados, provocando o enfraquecimento de determinadas cadeias produtivas industriais nacionais enquanto se fortaleciam cadeias produtivas ligadas às commodities minerais e agrícolas, como indica o gráfico 2. Ambos os gráficos foram elaborados com base nos dados do Ministério da Indústria, Comércio Exterior e Serviços. 
Gráfico 1: Participação de China e EUA nas exportações brasileiras (2000-2018)

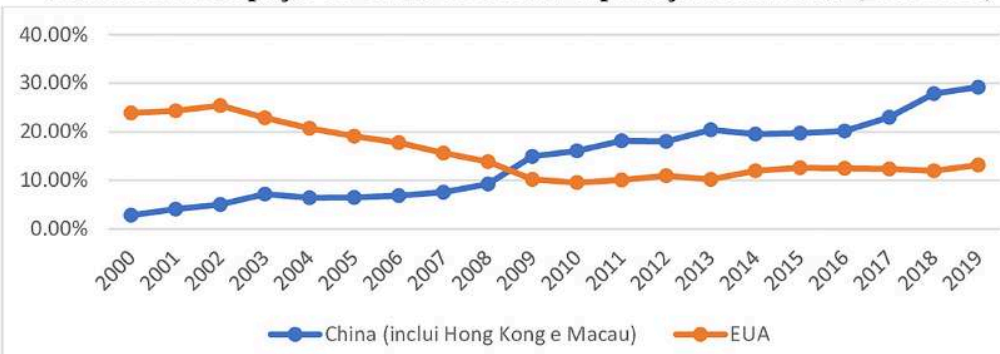

(Fonte: Ministério da Indústria, Comércio Exterior e Serviços)

Gráfico 2: Ex portações brasileiras por fator agregado (2000-2018)

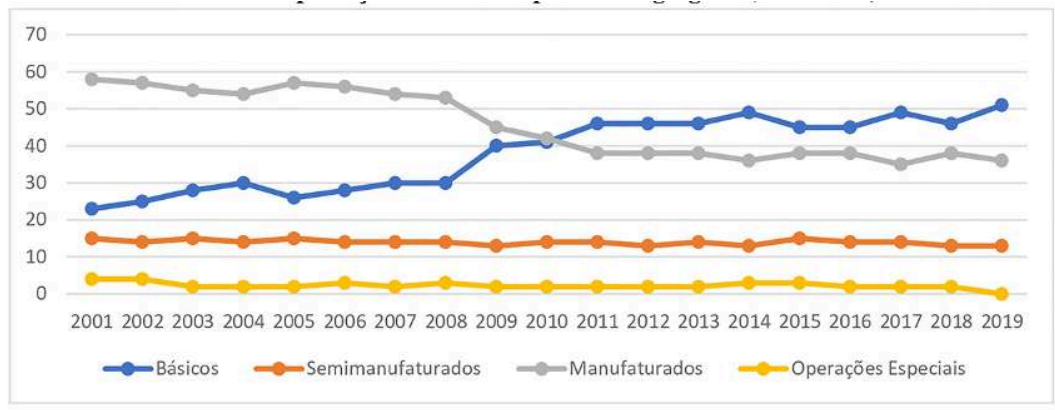

(Fonte: Ministério da Indústria. Comércio Fxterior e Servicos)

Especificamente, o complexo soja no Brasil alcançou um desempenho econômico excepcional ao longo das últimas décadas, tornando-se um dos mais importantes sustentáculos do atual padrão de articulação do país com o mercado internacional. Segundo o Instituto Brasileiro de Geografia e Estatística (IBGE), entre 2000 e 2018, a produção brasileira de soja saltou de 32,8 milhões de toneladas em 13,7 milhões de hectares para 117,9 milhões de toneladas em 34,8 milhões de hectares. Principal produtor brasileiro do grão no país hoje, o estado do Mato Grosso viu sua safra saltar de 8,8 milhões de toneladas em 2,9 milhões de hectares no ano 2000 para 31,6 milhões de toneladas em 9,4 milhões de hectares em 2018. Durante este período, a soja e seus derivados consolidaram-se dentre os principais produtos da pauta de exportações brasileira: segundo as séries históricas do Ministério da Indústria, Comércio Exterior e Serviços, as exportações brasileiras de soja em grãos, farelo e óleo 
saltaram de US\$ 4,2 bilhões, ou 7,5\% das exportações totais do país, em 2000 para US\$40,7 bilhões, ou 17\% das exportações totais do país, em 2018.

Este desempenho permitiu às burguesias agrária e agroindustrial reforçar sua posição dentre as frações da classe dominante que compõem o bloco no poder no Brasil. Acelerou-se neste período a construção de um "moderno" arco de relações que se estende desde conglomerados financeiros até instituições acadêmicas, responsável por apresentar o "agronegócio" como a melhor oportunidade de articulação do país com a economia internacional, por remover quaisquer obstáculos à expansão do mercado fundiário e de commodities e por multiplicar os canais de pressão e barganha no interior do Estado. Tomando-se a média do triênio 1999-2001 como referência, entre 2001 e 2010 o crédito rural concedido no Brasil cresceu $148 \%$ (9,5\% ao ano), composto por recursos públicos em $2 / 3$ do total. Subvenções financeiras inscritas no crédito rural totalizaram entre 2000 e 2010 cerca de $\mathrm{R} \$ 86,6$ bilhões de reais (a preços de 2010), cerca de $R \$ 7,9$ bilhões de reais anuais médios, distribuídos em subvenções de juros, subvenções da política de preços e subvenções para a rolagem da dívida agrária (Delgado, 2012: 103-104).

Ponta de lança neste processo, a assim chamada "bancada ruralista" dedica-se a articular em favor do "agronegócio" diversas modalidades de políticas públicas no campo brasileiro: distribuição desigual de crédito rural favorável a grandes produções, renegociação periódica das dívidas agrícolas, incentivos fiscais à conformação de distritos agroindustriais, construção de eixos modais de escoamento de produtos agropecuários destinados à exportação, etc. (Heredia, Palmeira e Leite, 2010: 166). Apesar de sua retórica modernizante, a bancada ruralista segue baseada na tríade relações de parentesco/ cargos públicos eletivos ou não/patrimônio fundiário, marca do atraso continuamente modernizado que perpetua oligarquias no interior do Congresso Nacional. Em pesquisa acerca dos membros desta bancada entre 1994 e 2010, foram identificados 408982 hectares em nome de deputados ruralistas e outros 434319 hectares em nome de empresas declaradas por deputados ruralistas, de acordo com dados do cadastro do Incra. Segundo Sandra Costa, cerca de $42,38 \%$ da área em nome de deputados ruralistas e 62,25\% da área em nome de suas empresas correspondiam a grandes propriedades improdutivas (Costa, 2012: 234-237). A autora destaca ainda como característica marcante na ação política ruralista a projeção de familiares a cargos eletivos municipais, estaduais e federais: levantamento de 08/2017 da Revista Congresso em Foco revelou que pelo menos 319 deputados (62\%) e 59 senadores (73\%) da legislatura em vigência tinham laços de sangue com outros representantes políticos, destacando a relevância das relações de parentesco para a perpetuação do poder econômico e político no Brasil. 


\section{Ascensão e crise dos governos do Partido dos Trabalhadores}

Neste contexto, os governos Lula entre 2003 e 2010 sacrificaram em escala crescente o compromisso histórico do Partido dos Trabalhadores com a reforma agrária. No início do primeiro mandato de Lula foi elaborado o II Plano Nacional de Reforma Agrária, cujas metas incluíam para o quadriênio 2003-2006: assentamento de 400 mil famílias, regularização fundiária de 500 mil posses e venda de terras para outras 150 mil famílias através do Programa Nacional de Crédito Fundiário (anterior Banco da Terra). No segundo mandato de Lula foi explicitamente abandonado qualquer projeto de democratização do acesso à terra no país, na medida em que não foi elaborado um novo Plano Nacional de Reforma Agrária para o período e o número de famílias assentadas caiu dramática e continuamente entre 2007 e 2010. Implementou-se em realidade uma aberta contra-reforma agrária, uma vez que a política fundiária deste quadriênio foi pautada por uma ampla legalização da grilagem de terras públicas na Amazônia Legal: as Medidas Provisórias 422 (Lei n. ${ }^{\circ}$ 11.763 de 01/08/2008) e 458 (Lei n. 11.952 de 25/06/2009) estabeleceram o programa Terra Legal e possibilitaram a regularização fundiária de ocupações de terras públicas na Amazônia Legal com até 15 módulos fiscais (isto é, até o máximo de 1500 hectares). Estabelecimentos com até 4 módulos fiscais ocupavam menos de $11,5 \%$ da área passível de regularização, enquanto estabelecimentos acima deste patamar ocupavam $88,5 \%$ da área regularizável (Théry, Mello, Hato e Girardi, 2012: 47).

Ao longo deste período esvaiu-se em grande medida a relevância política que o Movimento dos Trabalhadores Rurais Sem Terra (MST) havia conquistado ao longo da década de 1990. Por um lado, houve um decréscimo do número de ocupações de terra realizadas e de famílias sem terra acampadas no Brasil a partir de 2005 como resultado da redução da taxa de desemprego, da valorização do salário mínimo e da ampliação de políticas públicas de transferência de renda, que levaram a uma diminuição do apelo da reforma agrária dentre a base social mobilizada pelo MST. Por outro lado, houve uma opção política deste movimento pela manutenção da defesa de governos de centro-esquerda do Partido dos Trabalhadores que assentaram um número cada vez menor de famílias sem terra, mas ampliaram significativamente programas públicos para a agricultura familiar como o Programa Nacional de Educação na Reforma Agrária - Pronera (conjunto de projetos educacionais especificamente voltados para assentados e acampados), Programa de Aquisição de Alimentos - PAA (aquisição de produtos da agricultura familiar para o atendimento de populações em situação de insegurança alimentar) e Programa Nacional de Alimentação Escolar - PNAE (utilização de ao menos 30\% dos recursos da alimentação escolar pública na compra de produtos da agricultura familiar e dos assentamentos da reforma agrária). Soma-se a este quadro o fato 
de que o governo Lula não revogou, mas recuou na aplicação dos decretos e portarias baixados por Fernando Henrique Cardoso que haviam aprofundado a criminalização dos movimentos de luta pela terra ao final da década de 1990 .

Em seu $6{ }^{\circ}$ Congresso realizado em 2014, o Movimento dos Trabalhadores Rurais Sem Terra buscou enfrentar contradições de sua aliança com o governo federal através da perspectiva de construção da "reforma agrária popular" em contraponto à "reforma agrária clássica". Segundo esta proposta, o capitalismo mundial entre as décadas de 1980 e 1990 teria entrado em uma nova fase caracterizada pela hegemonia do capital financeiro que no Brasil teria levado ao aprofundamento do modelo do "agronegócio" e à inviabilização da realização de uma "reforma agrária clássica", baseada em uma aliança com aqueles setores mais progressistas da burguesia industrial para superar relações sociais atrasadas no campo e promover um desenvolvimento capitalista nacional relativamente autônomo. Em contraponto, a "reforma agrária popular" se basearia em uma aliança dos trabalhadores do campo e da cidade a partir de um projeto de desenvolvimento agroecológico para além dos limites do capitalismo, em um embate contra o latifúndio e contra o domínio do capital financeiro e de empresas transnacionais sobre o campo. Segundo esta leitura, a realização da "reforma agrária popular" teria como desafio central o acúmulo de forças dentre as massas trabalhadoras com vistas a democratizar o Estado, seja por meio da difusão no interior da sociedade civil dos projetos de reformas (com especial destaque à reforma agrária), seja por meio da eleição de mais representantes políticos comprometidos com esta concepção de desenvolvimento social e econômico. Nesse sentido, apesar da retórica radical da "nova concepção de reforma agrária", seu encaminhamento político não fez mais que reafirmar o caráter subsidiário do Movimento dos Trabalhadores Rurais Sem Terra aos projetos eleitorais do Partido dos Trabalhadores.

Ao longo da década de 2010, o MST realizou um esforço crescente em ocupar nichos de mercado especialmente de alimentos orgânicos, tanto diretamente por meio das feiras da reforma agrária realizadas em diversas cidades do país, quanto indiretamente por meio de parcerias entre o movimento e empresas do "agronegócio". Como exemplo, a compra anunciada durante a Rio +20 em junho de 2012 de 15 milhões de toneladas de arroz orgânico da Cooperativa de Produção Agropecuária Nova Santa Rita (RS) pelo Grupo Pão de Açúcar foi a maior transação já realizada entre o movimento e uma cadeia de supermercados, intermediada pelo programa Brasil Sem Miséria do governo federal (Correa, 2018: 93). No mesmo contexto, destaca-se também o lançamento de um fundo de investimentos no primeiro semestre de 2020 batizado de Finapop (Financiamento Popular), gerenciado em parceria entre cooperativas do MST e uma corretora de investimentos para possibilitar que pequenos investidores coloquem seu dinheiro em projetos sustentáveis da agricultura familiar em troca de um retorno pré-fixado pouco acima da 
valorização da poupança. Segundo reportagem do site do MST, a primeira cooperativa a ser financiada com um aporte de R \$ 1 milhão será justamente a Coopan (Cooperativa de Produção Agropecuária Nova Santa Rita - RS), considerada a maior produtora de arroz orgânico da América Latina, que também conta com sua criação própria e abatedouro de carne suína e leite. Em clara expressão de desencontro entre as elaborações ideológicas e a prática concreta de um movimento social, a despeito de sua retórica aparentemente radical, a assim chamada "reforma agrária popular" vem se caracterizando pelo crescente abandono da tática de ocupações de terra e por esforços de convivência pacífica com o "agronegócio". Atendendo a demandas das famílias assentadas vinculadas ao movimento e pressionado pela restrição de desapropriações para fins de reforma agrária ao longo da década de 2010, o MST tende cada vez mais claramente ao abandono de perspectivas de transformação radical das relações que historicamente caracterizaram a sociedade e o campo brasileiros. A trajetória do MST simboliza assim o estreitamento de horizontes da reforma agrária, considerada originalmente questão estratégica do processo de redemocratização do país e reduzida hoje à gestão da subalternidade da agricultura familiar face ao "agronegócio".

O impeachment da presidente Dilma Rousseff concluído em 08/2016 representou o coroamento da dialética que marcou os governos federais a partir de 2003, caracterizada pelo acúmulo de forças daqueles setores historicamente contrários ao Partido dos Trabalhadores e pelo enfraquecimento de movimentos populares que haviam atuado como esteio às conquistas eleitorais deste partido ao longo das últimas décadas. Entre 2010 e 2015 o número de assentamentos criados no Brasil diminuiu significativamente em comparação com o primeiro e o segundo governos Lula, equiparando os governos Dilma Rousseff apenas aos governos Fernando Collor/Itamar Franco quanto à reforma agrária. A nova queda a partir de 2010 no número de ocupações de terra foi causa e consequência deste retrocesso, levando ao paroxismo as contradições de movimentos de luta pela reforma agrária em apoio a um governo que se recusava explicitamente a aprofundá-la. Paralelamente, setores vinculados à grande propriedade fundiária e ao "agronegócio" aumentaram a capacidade de impor sua pauta à sociedade como um todo, com especial destaque para a aprovação do Novo Código Florestal (Lei n. ${ }^{\circ} 12.651$ de 25/05/2012). Apesar da continuidade de uma política agrária marcadamente conservadora e de uma política agrícola amplamente favorável ao "agronegócio", as principais entidades do setor, com exceções pontuais, apoiaram o impedimento da presidente Dilma Rousseff, na medida em que a chamada "bancada ruralista" garantiu 87 dos seus 92 votos em favor do impeachment (Lerrer, 2018: 96). Dentre as articulações políticas que tornaram isso possível, Lauro Mattei relata uma reunião ocorrida no dia 27/04/2016 entre a Frente Parlamentar da Agropecuária e Michel Temer em que teriam sido apresentadas as pautas do "agronegócio" pós-impeachment, 
com especial destaque para a extinção do Ministério do Desenvolvimento Agrário criado em 1999 e historicamente vinculado à defesa e promoção das políticas de reforma agrária (Mattei, 2016: 14). Coerentemente, dentre as primeiras ações do governo interino de $\mathrm{M}$ ichel Temer no meio rural, destacam-se a extinção deste Ministério e a atribuição de suas funções para um secretariado no novo Ministério do Desenvolvimento Social e Agrário, que seria extinto pelo futuro presidente eleito e sucedido pelo Ministério da Cidadania. O tenso balanço de forças que se materializara sob os governos Lula e Dilma e que se movera gradual e continuamente em desfavor dos movimentos sociais de luta pela terra culminou enfim em um novo contexto de deslegitimação radical de qualquer debate acerca da questão agrária no Brasil como problema econômico e político ainda vigente.

\section{Ascensão do governo Bolsonaro}

Nas eleições presidenciais de 2018 os principais setores do "agronegócio" aproximaram-se da candidatura de extrema-direita de Jair Bolsonaro, que significativamente alcançou seus melhores resultados nas regiões Sul e Centro Oeste. Segundo dados do Tribunal Superior Eleitoral, no primeiro turno Jair Bolsonaro recebeu 46,03\% dos votos em todo país, alcançando 56,8\% no Paraná, 65,8\% em Santa Catarina, 52,6\% no Rio Grande do Sul, 58,3\% no Distrito Federal, $60 \%$ em Mato Grosso, 57,2\% em Goiás e 55\% no Mato Grosso do Sul. No segundo turno Jair Bolsonaro recebeu 55,13\% dos votos no país, obtendo 68,43\% no Paraná, 75,9\% em Santa Catarina, 63,2\% no Rio Grande do Sul, 69,9\% no Distrito Federal, 66,4\% em Mato Grosso, 65,5\% em Goiás e 65,2\% no Mato Grosso do Sul. Dentre outras determinações, parece possível sustentar a hipótese de que inflexões político-culturais autoritárias representadas pela vitória de Jair Bolsonaro estão relacionadas ao fortalecimento de setores ligados à produção e comercialização de commodities agrícolas e agroprocessadas dentre frações da burguesia no bloco no poder. Evidências neste sentido durante os primeiros dois anos do governo Bolsonaro incluem a flexibilização pela Agência Nacional de Vigilância Sanitária (Anvisa) do marco legal para avaliação de riscos à saúde vinculados a agrotóxicos; a flexibilização de regras para posse de armas em regiões rurais do país; o aumento excepcional de focos de fogo no arco do desmatamento na região amazônica, em especial no estado do Mato Grosso; o congelamento da reforma agrária e da demarcação de terras indígenas e quilombolas; a multiplicação de atos infralegais com objetivo de flexibilizar a legislação ambiental. Ademais, a Medida Provisória 910 de 2019 tentou promover a terceira flexibilização em dez anos das condições de regularização das terras públicas invadidas na Amazônia, estendendo a data-limite 
de ocupações beneficiadas de 22/07/2008 para 05/05/2014 e ampliando de 4 para 15 módulos fiscais a dimensão dos imóveis cujos requisitos de regularização seriam declarados pelo próprio ocupante e isentos de vistoria prévia in loco. Com a medida, o governo Bolsonaro também se propunha conceder títulos definitivos de propriedade a pessoas que ainda não o detêm em assentamentos de reforma agrária, incorporando potencialmente ao crédito bancário e ao mercado de terras os lotes de cerca de 700 mil famílias sem titulação em 2019 segundo declaração do presidente do Instituto N acional de Colonização e Reforma Agrária (Incra). Apesar da fragilidade crônica da oposição e do apoio da Frente Parlamentar Agropecuária, esta Medida Provisória não conseguiu ser aprovada em meio ao contínuo agravamento da crise política do governo Bolsonaro durante a pandemia de covid-19 no primeiro semestre de 2020 .

O acirramento do desmatamento, sobretudo na região amazônica, durante os primeiros dois anos do governo de Jair Bolsonaro é de fato a evidência mais nítida do fortalecimento de frações das classes dominantes brasileiras tradicionalmente vinculadas à grande propriedade fundiária. Para que o Brasil se tornasse hoje uma espécie de plataforma de produção de commodities agrícolas para o mercado internacional, as modernas lavouras de cana de açúcar e de grãos avançaram ao longo das últimas décadas sobre aquelas áreas que haviam sido anteriormente desflorestadas para a formação de pasto para pecuária bovina. A expansão da lavoura de cana de açúcar na região Sudeste e o avanço da sojicultura na região Centro Oeste vêm pressionando o deslocamento do gado bovino em direção ao Norte, consequentemente contribuindo de maneira indireta para a ampliação do arco do desflorestamento na região amazônica. Uma demonstração estatística para este fenômeno foi oferecida pela primeira vez por artigo de 2011, segundo o qual no período entre 2003 e 2008 uma redução em 10\% da expansão da soja sobre antigas áreas de pastos teria diminuído em até 40\% o desmatamento nos 761 municípios da Amazônia Legal englobados no estudo (Arima et al., 2011). Em particular no Norte mato-grossense e no Sul do Pará, reproduz-se sucessivamente uma pecuária de baixa produtividade a partir de ocupantes iniciais que desmatam, queimam a floresta, geralmente não investem na limpeza apropriada do solo e obtêm lucro prioritariamente através da venda da área para produtores mais capitalizados e com maior acesso à informação, que por sua vez estabelecem suas fazendas com produção em maior escala e mais intensiva em tecnologia (Arima et al., 2005: 20). Dados da tabela 1 confirmam o impulso do rebanho bovino em direção à fronteira amazônica: no período entre 1990 e 2017 a região Norte aumentou sua participação no efetivo de gado bovino no país de $9,1 \%$ para $22,6 \%$, enquanto o Sul diminuiu sua participação de $17,2 \%$ para $12,6 \%$ e o Sudeste de $24,7 \%$ para $17,5 \%$. 
Tabela 1: Efetivo de rebanho bovino por Grande Região no Brasil de 1990 a 2017

\begin{tabular}{|c|c|c|c|c|c|c|c|c|}
\hline Regiões & 1990 & $\%$ & 2000 & $\%$ & 2010 & $\%$ & 2017 & $\%$ \\
\hline Norte & 13.316 .950 & 9,1 & 24.517 .612 & 14,4 & 42.100 .695 & 20,1 & 48.471 .454 & 22,6 \\
\hline Nordeste & 26.190 .283 & 17,8 & 22.566 .644 & 13,3 & 28.762 .119 & 13,7 & 27.736 .607 & 12,9 \\
\hline Sudeste & 36.323 .168 & 24,7 & 36.851 .997 & 21,7 & 38.251 .950 & 18,3 & 37.529 .834 & 17,5 \\
\hline Sul & 25.325 .979 & 17,2 & 26.297 .970 & 15,5 & 27.866 .349 & 13,3 & 27.033 .684 & 12,6 \\
\hline Centro Oeste & 45.945 .934 & 31,2 & 59.641 .301 & 35,1 & 72.559 .996 & 34,6 & 74.128 .217 & 34,5 \\
\hline Total & 147.102 .314 & 100 & 169.875 .524 & 100 & 209.541 .109 & 100 & 214.899 .796 & 100 \\
\hline
\end{tabular}

(IBGE - Pesquisa da Pecuária Municipal)

Neste contexto, há também evidências de tensões entre o governo Bolsonaro e sua base no "agronegócio", inicialmente devido a pressões pontuais da equipe econômica ultraliberal para reduzir subsídios ao setor e devido a alinhamentos geopolíticos aos EUA capazes de ameaçar os mercados internacionais de algumas commodities brasileiras. Tais tensões elevaram-se com as declarações de membros do primeiro escalão do governo Bolsonaro e de seus familiares durante a pandemia de covid-19 no início de 2020, responsabilizando diretamente a China e seus interesses geopolíticos pela criação e propagação do novo vírus, que então paralisou de modo inédito parte da economia global. Como resposta imediata, o governo chinês ameaçou no início de abril de 2020 aumentar as importações de soja dos Estados Unidos e reduzir as compras do grão brasileiro. Ainda nesse contex to, a aceleração do desmatamento na floresta amazônica levou ao aumento da insatisfação de empresas do "agronegócio" vinculadas ao mercado europeu, principalmente após a ameaça em junho de 2020 de empresas de investimento europeias de desinvestir em produtores de carne, operadoras de grãos e títulos do governo no Brasil. Como reação, os frigoríficos e as tradings em operação no país começaram a advogar pela demissão do então ministro do Meio Ambiente Ricardo de Aquino Salles, defendido pelas demais forças ruralistas por sua flexibilização da legislação ambiental. Ruídos como estes são uma ilustração das cisões e dos limites das pretensões hegemônicas do chamado "agronegócio" dentro do bloco no poder no Brasil. 
Nesse sentido, o fortalecimento político do chamado "agronegócio" e seu desempenho econômico acima da média nacional não parecem ser capazes de dar qualquer resposta estável à crise de hegemonia que vem corroendo a institucionalidade política no Brasil. Pelo contrário, a incapacidade do bolsonarismo de construir consenso entre as frações da classe dominante para o exercício da hegemonia sobre as classes subalternas parece apontar para um crescente protagonismo político das Forças Armadas no Brasil. Segundo o Painel Estatístico de Pessoal do Ministério da Economia, o número de militares da ativa do Exército, da Marinha e da Aeronáutica cedidos para cargos de confiança no Executivo Federal aumentou de 1137 em 01/1999 para 1925 em 01/2019, usualmente com atuação restrita a três órgãos: Ministério da Defesa, Vice-Presidência e Presidência da República (mais especificamente, o Gabinete de Segurança Institucional). Volvido apenas um ano e meio de gestão Bolsonaro, a participação de militares da ativa no governo federal aumentou $33 \%$, para 2558, até 07/2020, com atuação diversificada em ao menos 18 órgãos dos Ministérios da Saúde, Economia, Família e Minas e Energia. Neste mesmo sentido, entre 01/2019 e 07/2020, o número de ministros que possuem origem militar aumentou de 7 para 10, dentre os 23 que compõem o governo Bolsonaro. Em uma espécie de eterno retorno, o processo de modernização da sociedade brasileira parece uma vez mais recorrer ao autoritarismo aberto e à tutela militar para garantir a permanente atualização de alguns dos traços de nosso passado colonial e escravista.

Segundo o Banco de Dados de Luta pela Terra (Dataluta), entre 1979 e 2016 tinham sido criados em todo o país 9444 assentamentos de reforma agrária, reunindo 1127078 famílias em 82159838 hectares; porém, ao longo de todo este período as políticas de reforma agrária mantiveram-se no interior dos estreitos limites estabelecidos pela subordinação da renda da terra ao capital, tanto por meio de superindenizações nos casos de desapropriações por interesse social, quanto por meio da compra e venda de propriedades financiada pelo Banco da Terra. Como resultado, a maior parte dos assentamentos foi criada em regiões com grande quantidade de terras públicas ou com terras privadas com menor valor de mercado: durante o período entre 1979 e 2016, a região Norte concentrou 44,8\% das famílias assentadas e 74,6\% da área dos assentamentos de reforma agrária (Dataluta, 2017). Milhares de famílias encontraram nesses locais condições de vida e trabalho mais dignas que aquelas disponíveis em periferias de pequenos, médios e grandes centros urbanos, mas parte dos beneficiários do programa de reforma agrária abandonou seus lotes por diversos motivos: dificuldades de transporte e acesso a escolas e hospitais; falta de apoio à produção e infraestrutura precária de escoamento e comercialização; endividamento e dificuldade em lidar com a burocracia de instituições de crédito; imposição tanto por organizações de trabalhadores quanto por organismos estatais de regras estranhas às experiências anteriores 
dos assentados; pressões e ameaças de grandes proprietários, especialmente enquanto o Incra não regulariza a situação da área (Medeiros, 2003: 84). Como resultado destes limites e contradições, a política de reforma agrária durante a Nova República mostrou-se até o momento incapaz de promover qualquer alteração significativa na estrutura fundiária no país: entre 1985 e 2017 diminuiu a participação de estabelecimentos com menos de 100 ha na área total ocupada (de 21,21\% para 20,49\%), enquanto ampliou-se consideravelmente a participação de estabelecimentos com mais de 1000 ha na área ocupada por estabelecimentos rurais no Brasil (de 43,73\% para 47,53\%). Em meio à perpetuação da concentração de poder econômico e político no campo, ocorreram 1965 assassinatos de trabalhadores rurais no Brasil entre 1985 e 2019 segundo a Comissão Pastoral da Terra (CPT), dois terços deles em estados da Amazônia Legal com destaque para Pará, Maranhão, Rondônia e Mato Grosso, conforme dados da tabela 2. Neste contexto, podemos sustentar a hipótese de que o fracasso das políticas de reforma agrária ao longo das últimas décadas em reverter ou ao menos minimizar esta herança histórica de nossa formação colonial e escravista é um dos fatores a determinar o atual colapso do ciclo de redemocratização iniciado em 1985.

Tabela 2: Estrutura fundiária no Brasil de 1985 a 2017

\begin{tabular}{|c|c|c|c|c|c|c|c|c|}
\hline \multirow{2}{*}{$\begin{array}{l}\text { Classes de } \\
\text { área (ha) }\end{array}$} & \multicolumn{8}{|c|}{ Número de estabelecimentos } \\
\hline & 1985 & $\%$ & 1996 & $\%$ & 2006 & $\%$ & 2017 & $\%$ \\
\hline Menos de 10 & 3.064 .822 & 52,91 & 2.402 .374 & 49,65 & 2.447 .151 & 50,04 & 2.543 .778 & 50,93 \\
\hline 10 a 100 & 2.160 .340 & 37,29 & 1.916 .487 & 39,61 & 1.971 .600 & 40,31 & 1.979 .915 & 39,64 \\
\hline 100 a 1.000 & 517.431 & 8,93 & 469.964 & 9,71 & 424.288 & 8,68 & 420.136 & 8,41 \\
\hline Mais de 1.000 & 50.411 & 0,87 & 49.358 & 1,02 & 47.578 & 0,97 & 50.865 & 1,02 \\
\hline Total & 5.793 .004 & 100 & 4.838 .183 & 100 & 4.890 .617 & 100 & 4.994 .694 & 100 \\
\hline \multirow{2}{*}{$\begin{array}{l}\text { Classes de } \\
\text { área (ha) }\end{array}$} & \multicolumn{8}{|c|}{ Área Ocupada (ha) } \\
\hline & 1985 & $\%$ & 1996 & $\%$ & 2006 & $\%$ & 2017 & $\%$ \\
\hline Menos de 10 & 9.986 .637 & 2,66 & 7.882 .194 & 2,23 & 7.798 .777 & 2,34 & 7.989 .114 & 2,28 \\
\hline 10 a 100 & 69.565 .161 & 18,55 & 62.693 .585 & 17,73 & 62.893 .979 & 18,85 & 63.783 .346 & 18,21 \\
\hline 100 a 1.000 & 131.432 .667 & 35,06 & 123.541 .517 & 34,94 & 112.844 .186 & 33,82 & 112.029 .612 & 31,98 \\
\hline Mais de 1.000 & 163.940 .463 & 43,73 & 159.493 .949 & 45,10 & 150.143 .096 & 45,00 & 166.451 .258 & 47,53 \\
\hline Total & 374.924 .928 & 100 & 353.611 .245 & 100 & 333.680.038 & 100 & 350.253.330 & 100 \\
\hline
\end{tabular}


Tabela 3: Número de assassinatos em conflitos pela terra no Brasil de 1985 a 2019

\begin{tabular}{c|c|c|c|c|c|c|c|c|c|c}
\hline & $\mathbf{1 9 8 5}-$ & $\mathbf{1 9 9 0}$ & $\mathbf{1 9 9 5}-\mathbf{1 9 9 9 -}$ & $\mathbf{2 0 0 3 -}$ & $\mathbf{2 0 0 7 -}$ & $\mathbf{2 0 1 1}$ & $\mathbf{2 0 1 5}$ & $\mathbf{2 0 1 9}$ & Total \\
\hline Amapá & 0 & 5 & 1 & 0 & 0 & 0 & 0 & 0 & 1 & $\mathbf{2 0 1}$ \\
\hline Roraima & 8 & 0 & 0 & 0 & 2 & 1 & 5 & 1 & 0 & $\mathbf{1 7}$ \\
\hline Acre & 11 & 2 & 1 & 3 & 0 & 1 & 2 & 0 & 0 & $\mathbf{2 0}$ \\
\hline Rondônia & 29 & 6 & 13 & 4 & 12 & 8 & 17 & 64 & 1 & $\mathbf{1 5 4}$ \\
\hline Amazonas & 8 & 3 & 6 & 1 & 2 & 4 & 4 & 6 & 6 & $\mathbf{4 0}$ \\
\hline Pará & 293 & 86 & 68 & 42 & 89 & 45 & 33 & 63 & 12 & $\mathbf{7 3 1}$ \\
\hline Maranhão & 58 & 34 & 12 & 3 & 10 & 9 & 18 & 24 & 4 & $\mathbf{1 7 2}$ \\
\hline Goiás & 16 & 3 & 3 & 0 & 1 & 2 & 0 & 0 & 0 & $\mathbf{2 5}$ \\
\hline $\begin{array}{c}\text { Mato Grosso } \\
\text { Tocantins }\end{array}$ & 56 & 24 & 7 & 4 & 18 & 9 & 9 & 14 & 3 & $\mathbf{1 4 4}$ \\
\hline $\begin{array}{c}\text { Soma das } \\
\text { Unidades da } \\
\text { Federação da } \\
\text { Amazônia } \\
\text { Legal }\end{array}$ & $\mathbf{4 9 9}$ & $\mathbf{1 7 4}$ & $\mathbf{1 1 5}$ & $\mathbf{5 8}$ & $\mathbf{1 3 6}$ & $\mathbf{8 2}$ & $\mathbf{8 8}$ & $\mathbf{1 5 1}$ & $\mathbf{0}$ & $\mathbf{1 . 3 0 3}$ \\
\hline $\begin{array}{c}\text { Demais } \\
\text { Unidades da } \\
\text { Federação }\end{array}$ & $\mathbf{2 1 9}$ & $\mathbf{1 0 5}$ & $\mathbf{4 7}$ & $\mathbf{5 8}$ & $\mathbf{5 6}$ & $\mathbf{3 8}$ & $\mathbf{4 8}$ & $\mathbf{3 5}$ & $\mathbf{5}$ & $\mathbf{6 1 1}$ \\
\hline \begin{tabular}{c} 
Brasil \\
\hline
\end{tabular} & $\mathbf{7 1 8}$ & $\mathbf{2 7 9}$ & $\mathbf{1 6 2}$ & $\mathbf{1 1 6}$ & $\mathbf{1 9 2}$ & $\mathbf{1 2 0}$ & $\mathbf{1 3 6}$ & $\mathbf{2 1 0}$ & $\mathbf{3 2}$ & $\mathbf{1 . 9 6 5}$ \\
\hline
\end{tabular}

\section{Conclusão}

Dentre outros vetores, o bolsonarismo pode ser interpretado como resultado de uma contradição central do complexo de relações sociais atualmente conhecido como "agronegócio". Esta prática social do Brasil contemporâneo corresponde com precisão ao conceito de espaço abstrato proposto por Henri Lefebvre, referente à produção do espaço sob o que se convencionou denominar "globalização" ao longo da segunda metade do século $X X$. Segundo este autor, a contradição entre um espaço integrado (em escala global) e um espaço segregado (em escala local) tende a desdobrar-se na produção de centros de poder cada vez mais opacos e autoritários que mobilizam práticas crescentemente autocráticas (Lefebvre, 2013: 319).

Em uma síntese que corresponde com perfeição ao assim chamado "agronegócio", Lefebvre argumenta que o espaço abstrato tende à homogeneidade por ser suporte da generalização da forma mercadoria, mas também por tornar crescentemente a própria terra um objeto de intercâmbio e investimento que 
subordina diferenças qualitativas ao imperativo quantitativo da valorização do valor. Simultânea e contraditoriamente, Lefebvre aponta que o espaço abstrato se fragmenta à medida que é vendido em parcelas e amplia a segregação de elementos sociais rechaçados às periferias, ordenando a distribuição e os fluxos de grupos e classes de acordo com uma divisão social do espaço que complexifica as contradições da divisão social do trabalho. Como consequência desta contradição, o autor conclui que o espaço abstrato se hierarquiza não apenas porque distribui as classes em locais tidos como periféricos, desprezíveis, perigosos ou centrais, nobres, atraentes, mas principalmente porque exige centros de poder político que se reforçam face aos conflitos decorrentes de um espaço ao mesmo tempo globalizado e fragmentado (Lefebvre, 2013: 325).

Desde esta perspectiva, esperamos ter demonstrado neste artigo que as contradições da produção do espaço sob o "agronegócio" são fundamentais à compreensão das tendências autoritárias que vêm atualmente colocando em xeque a frágil e recente democracia brasileira. Dentro deste contexto, o bolsonarismo pode ser interpretado como um momento no interior de um processo de aprofundamento da integração do Brasil às cadeias internacionais de com modities, que vem perpetuando e multiplicando clivagens sociais que marcam nossa formação histórica. Neste sentido, o sentido histórico do impulso autocrático que caracteriza o governo Bolsonaro é a reafirmação dos abismos sociais de nosso passado e presente como naturais e inelimináveis, aprisionando-nos a uma espécie de eterno retorno de nossa via colonial de formação capitalista.

\section{Referências bibliográficas}

ARIMA, Eugênio, BARRETO, Paulo, BRITO, Marky (2005), Pecuária na Amazônia: tendências e implicações para a conservação ambiental, Belém, Instituto do Homem e Meio Ambiente da Amazônia.

ARIMA, Eugênio, RICHARDS, Peter, WALKER, Robert, CALDAS, Marcellus (2011), "Statistical confirmation of indirect land use change in the Brazilian Amazon", Environmental Research Letters, Volume 6, Number 2, 1-7.

CORREA, Ana Elisa Cruz (2018), Crise da modernização e gestão da barbárie: a trajetória do MST e os limites da questão agrária, Tese de Doutorado em Serviço Social, Universidade Federal do Rio de Janeiro (UFRJ), Rio de Janeiro.

COSTA, Sandra Helena Gonçalves (2012), A questão agrária no Brasil e a bancada ruralista no Congresso Nacional, Dissertação de mestrado em Geografia, Universidade de São Paulo (USP), São Paulo.

DATAlUTA (2017), Relatório Brasil 2016, Núcleo de Estudos, Pesquisas e Projetos de Reforma Agrária, Faculdade de Ciência e Tecnologia, Universidade Estadual Paulista (Unesp), Presidente Prudente. 
DELGADO, Guilherme (2012), Do capital financeiro na agricultura à economia do agronegócio: Mudanças cíclicas em meio século, Porto Alegre, Editora da UFRGS.

HEREDIA, Beatriz, PALMEIRA, Moacir, LEITE, Sérgio (2010), "Sociedade e economia do “agronegócio" no Brasil”, Revista Brasileira de Ciências Sociais, vol. 25, n. 74, 159-176.

LEFEBVRE, Henri (2013), La producción del espacio, Madrid, Capitán Swing.

LERRER, Débora (2018), “A visibilidade e o silenciamento do problema agrário brasileiro nos anos FHC e Lula", in Fabiano Coelho e Rodrigo Simão Camacho (orgs.), O campo no Brasil contemporâneo: do governo FHC aos governos petistas, Volume 1, Curitiba, Editora CRV.

MATTEI, Lauro Francisco (2016), O governo interino e a desestruturação da política agrária e de desenvolvimento rural do país, Texto para discussão 018/2016, Núcleo de Estudos de Economia Catarinense, Universidade Federal de Santa Catarina, Florianópolis.

MEDEIROS, Leonilde (2003), Reforma agrária no Brasil: História e atualidade da luta pela terra, São Paulo, Editora Fundação Perseu Abramo.

THÉRY, Hervé, MELLO, Neli Aparecida de, H ATO, Julio, GIRARDI, Eduardo (2009), Atlas do Trabalho Escravo no Brasil, São Paulo, Amigos da Terra.

- Receção: 29-09-2020

- Aprovação: 30-01-2021 